\title{
ANÁLISIS DE TEXTOS LITERARIOS INFANTILES: AVANZANDO EN LA DES- CONSTRUCCIÓN DE CÓDIGOS PATRIARCALES
}

\author{
Sylvia Contreras Salinas \\ Universidad Complutense de Madrid \\ Mónica Ramírez Pavelic \\ Universidad Autónoma de Madrid
}

\begin{abstract}
Resumen: Este artículo presenta una reflexión realizada desde la perspectiva del feminismo como teoría crítica que intenta visibilizar distorsiones en la perspectiva de género. Para ello se analizaron los textos ganadores del primer concurso infantil de literatura con enfoque de género, realizado y coordinado por el Ministerio de Educación de Chile en el año 2008. Las preguntas que orientaron nuestro trabajo fueron: ¿Qué dicen niños y niñas sobre las relaciones de géneros en sus creaciones literarias? Así como ¿porqué fueron seleccionados los textos ganadores? Entre los hallazgos más significativos encontramos que a pesar del contexto global los textos ganadores encajan en el sistema patriarcal, notándose la ausencia de otras prácticas discursivas presentes en el contexto nacional e internacional.

Palabras claves: género; creaciones literarias infantiles; políticas de equidad; equidad de género en Chile.
\end{abstract}

La no discriminación por razones de sexo y la igualdad entre hombres y mujeres sonun derecho constitucional que en la actualidad nadie discute; más aún, esta exigencia se plasma en la mayoría de las acciones y propuestas de las organizaciones nacionales e internacionales cuyo objetivo es mejorar la calidad de vida de todas las personas. ${ }^{1}$ Así es como se aprecian los numerosos convenios y programas que buscan resguardar el derecho de la mujer y la igualdad de oportunidades. En este contexto encontramos los Objetivos de

Copyright ( $\odot 2011$ by Revista Estudos Feministas.

' Las autoras agradecen a Miryam Carreño (Universidad Complutense de Madrid) y David Poveda (Universidad Autónoma de Madrid) la ayuda prestada en la revisión de este artículo. Además a los/as tres árbitros de este. 
Desarrollo del Milenio - ODM; ${ }^{2}$ en esta misma línea hallamos también La Convención Internacional sobre la Eliminación de Todas las Formas de Discriminación contra la Mujer CEDAW, La Convención Interamericana para Prevenir, Sancionar y Erradicar la Violencia contra la Mujer - MESECVI y los documentos emanados de las Conferencias de Naciones Unidas a nivel regional y mundial, principalmente la Plataforma de Acción de Beijing, el Programa de Acción de El Cairo, la Declaración de Viena, además de los Programas de Acción Regional para las mujeres de América Latina y el Caribe, entre otros. Todos ellos apuntan a la superación de la discriminación contra las mujeres y constituyen una oportunidad para avanzar en materia de equidad de género.

Chile, por su parte, desde la década de los noventa, con el reinicio de los gobiernos democráticos, se ha planteado formalmente el propósito de disminuir las desigualdades que viven muchas mujeres chilenas. Es así como en 1992 se da inicio a éste complejo proceso, con la creación del Servicio Nacional de la mujer, para continuar con la formulación de planes de igualdad de oportunidades: el primero entre 1991 y 1999, el segundo desde 2000 a 2010; dicho proceso buscaría consolidar la transversalización ${ }^{3}$ de género. En este contexto se crea en el año 2000 el Consejo de Ministros para la igualdad de oportunidades, como un plan estratégico que buscaba supervisar y monitorear mejoras en las oportunidades de mujeres y hombres en relación a las políticas públicas, destacándose un doble carácter: político - avanzar en materia de equidad eliminando la discriminación contra la mujer - y técnico - los compromisos se situarían en el ámbito local e institucional para su implementación. En este sentido se señala que

la tarea de avanzar en equidad de género, por ser un bien público, es transversal a los distintos ministerios y sectores del Estado. Ninguno de estos actores está exento de responsabilidad y de compromiso, tanto en relación a recursos humanos como materiales para la consecución de las metas que se acuerden al $2010 .^{4}$

Del último periodo que le correspondió presidir a Michelle Bachelet, rescatamos los siguientes objetivos:

- eliminar o reducir la discriminación en contra de las mujeres;

- eliminar o reducir las brechas que existen entre mujeres y hombres, pero también aquellas que existen entre mujeres;

- ampliar los derechos y responsabilidades de las mujeres en el ámbito público y de los varones en el ámbito privado, contribuyendo a hacer más igualitarias las relaciones entre los géneros; y

- contribuir al empoderamiento de las mujeres como sujetos sociales.

Estos propósitos se establecen considerando que según los estudios realizados por los Ministerios, y a pesar de las reformas legales y los planes de igualdad de oportunidades, en Chile aún existen mujeres discriminadas, que ganan menos que los hombres, pagan más en los seguros de salud, siguen sobrellevando la mayor parte del trabajo doméstico y tienen baja representación en los cargos directivos. Al respecto, un estudio realizado en el 2010 por la Universidad de Chile en conjunto con Comunidad Mujer a 3.000 mujeres entre 18 y 65 años de todo el país revela que dos de cada tres mujeres llegan a su casa después

2 ONU, 2009.

${ }^{3}$ Estrategias para valorar y considerar todas las preocupaciones y experiencias de hombre y mujeres en el diseño, implementación, monitoreo y evaluación de políticas y programas en todas las esferas, de modo que ambos se beneficien igualitariamente.

${ }^{4}$ Agenda de Gobierno de Chile para avanzar en equidad de género (2006-2010). 
del trabajo a hacer tareas domésticas. En cambio, sólo el 2,07\% de los hombres realiza la misma labor; del total de la muestra, el $54 \%$ de las entrevistadas afirman tener una ocupación. Entre las conclusiones destaca el cuestionamiento en los avances en igualdad de género. Complementario a este estudio, el Instituto Nacional de Estadística - INE realizó un estudio exploratorio en Santiago de Chile, corroborando que las mujeres llevan el peso de las tareas domésticas: un $77,8 \%$ de ellas dedica 3,9 horas diarias a estas labores (sólo un $22,2 \%$ no las hace), contra un $40,7 \%$ de los hombres que las realizan por 2,6 horas (un $59,3 \%$ está ajeno a ellas). La situación empeora cuando ambos cónyuges trabajan remuneradamente; ahí la participación de la mujer en las tareas del hogar alcanza a un $81,7 \%$ versus un $36,3 \%$, cifra que se eleva a un $93 \%$ los fines de semana, contra un $56,8 \%$ ). ${ }^{5}$

En este contexto, adquiere relevancia en la Agenda de Gobierno de Bachelet la idea que las mujeres no sólo tengan los mismos derechos que los hombres, sino que además tengan la posibilidad de ejercerlos, por tanto se declara que se apoyará del modo más decidido el ejercicio efectivo de los derechos de la mujer. ${ }^{6}$ Así, cada ministerio contaría con una agenda ministerial de equidad de género, donde se precisan tareas para ser abordadas de modo conjunto y coordinado. En este marco, en el sector de educación se formulan variados objetivos, entre ellos:

- implementar el enfoque de equidad género desde la educación parvularia en la actualización curricular de la educación básica y media;

- revisar los textos escolares, programas de estudio y las prácticas docentes para eliminar el sexismo que limita las opciones de desarrollo de las niñas;

- capacitar a profesoras/es para que desarrollen prácticas educativas no sexistas. En este contexto destaca la implementación de curso piloto de educación a distancia Género, sexualidad: competencias para la docencia, que nace como respuesta a las deficiencias detectadas en la formación inicial de futuros/as docentes. Esta iniciativa se enmarca en el convenio de colaboración entre el Centro Latinoamericano de Sexualidad y Derechos Humanos - CLAM, el Centro de Estudios para el Desarrollo de la Mujer - CEDEM y la Universidad Arturo Prat de Chile; basado en un modelo desarrollado en Brasil, el curso adapta sus contenidos a la realidad chilena. Esta experiencia buscaría la reflexión acerca de conceptos como género y sexualidad, ente otros, para permitir a los docentes guiar a los/as estudiantes en sus discusiones y reflexiones. ${ }^{7}$ Señalar, además, las acciones del Centro de Perfeccionamiento, Experimentación e Investigación Pedagógica - CPEIP en sus programas de formación de apropiación curricular con perspectiva de género, que realiza en conjunto con 29 universidades del país;

- ampliar la educación en sexualidad y afectividad para que niñas y niños tengan un desarrollo integral como personas;

- incentivar en los/as niños/as, adolescentes y jóvenes una mirada crítica a las formas tradicionales de masculinidad; y

- promover la incorporación en las universidades de una asignatura obligatoria sobre derechos humanos y género en las distintas carreras, especialmente en la formación de los/as docentes.

${ }^{5}$ EL MERCURIO, 30 marzo 2009.

${ }^{6}$ Michelle BACHELET, 2006.

7 OBSERVATORIO DE GÉNERO Y EQUIDAD, 2010.

${ }^{8}$ Agenda de Gobierno de Chile para avanzar en equidad de género (2006-2010). 
Visto lo anterior, parece evidente que la educación se presenta como el pilar fundamental para alcanzar los objetivos propuestos a corto, mediano y largo plazo, es decir, ella sería la base de las oportunidades.

Destaca también la tarea de apoyar comunicacionalmente campañas que permitan reflexionar sobre la discriminación de género en el sistema educativo y promover una imagen positiva de la mujer. ${ }^{9} \mathrm{Al}$ respecto, la ex mandataria postulaba:

nada de lo que hagamos tendrá pleno sentido si no lo palpan los ciudadanos allí donde viven, en sus ciudades y regiones, en sus calles y pasajes. Que lo note el trabajador, el estudiante y la dueña de casa. Que se note en las escuelas, en el paradero, en el juzgado, en el consultorio y en la casa. ${ }^{10}$

\section{Concurso literario con enfoque de género}

Nos ha parecido relevante detenernos tan extensamente en el proceso institucional que se ha llevado a cabo en Chile desde las década de los noventa hasta inicios del 2010, pues esto clarifica el contexto global en que se inscribe la iniciativa del primer concurso de poesía y cuento infantil con enfoque de género 2008 , nacido con el propósito de contribuir a desarrollar habilidades imaginativas, incorporando y asimilando desde la niñez el tema de igualdad plena para hombres y mujeres, y cuyo objetivo principal era contribuir en la construcción de una cultura de igualdad de género desde la escuela y en la escuela, con la participación de toda la comunidad educativa. En este sentido, la ministra de Educación, Mónica Jiménez, afirma:

Si no se llama la atención sobre la igualdad que debe regir entre todos los seres humanos desde pequeños, si no se crea esa cultura desde ese momento, se ha perdido un tiempo precioso. Pero, otra tarea no menos dificultosa es lograr que los adultos seamos capaces de trasmitir una cultura de la igualdad plena entre los distintos géneros. A veces no somos ni siquiera capaces de descifrar los códigos con que se enquista la desigualdad en nuestro lenguaje, en las relaciones, incluso en los gestos."

Este primer concurso buscaba abrir un espacio para que niños y niñas, con edades comprendidas entre 8 y 16 años, plasmaran en sus creaciones literarias los significados, las nociones, las definiciones que construyen en torno a las diferencias entre hombres y mujeres, y a la relación que ambos construyen. De esta manera se supone que los/as niños/as apoyados/as por sus respectivos/as docentes - reflexionarían en torno a los roles de género construidos cultural y socialmente, además de analizar sus significaciones y alcances.

Para ello se definió que la propuesta considerara tres importantes momentos: primero, el trabajo de análisis y reflexión en el aula entre docentes y estudiantes: el concurso buscaba que los/as niños/as tomaran conciencia o fueran capaces de reconocer hechos y situaciones y reflexionaran sobre ello. En este sentido, era esperable que los/as docentes propusieran conversaciones sobre tales temáticas, de acuerdo a las etapas y experiencias propias de cada nivel y contexto social; el segundo momento buscaba la creación de textos; y el tercero implicaba la selección por parte de un jurado de las creaciones que se ajustaran a los requerimientos estipulados en las bases:

El tema debe enmarcarse dentro de cualquier ámbito de la vida, pero debe aludir, debe contemplar el enfoque de género. La diversidad de temas y ámbitos es muy

9 SERNAM, 2005.

${ }^{10}$ BACHELET, 2006.

$"$ CHILE, 2009a.

576 Estudos Feministas, Florianópolis, 19(2): 573-590, maio-agosto/201 1 
amplia, puede ser cualquiera, siempre y cuando se tenga en cuenta la dimensión de diferencias, desigualdades o inequidades entre hombre y mujer, niño y niña, etc. ${ }^{12}$

A modo de ejemplo, sugerimos que el/la profesor/a ponga a discusión temas como actividades "no tradicionales", cambios de los roles en el transcurso del tiempo, opción por estudios no tradicionales para cada sexo etc.

La periodista que cubrió la premiación de este concurso refiere que

los miembros del jurado, integrado por los escritores: Eledín Parraguez, Reinaldo Marchant y la poetisa Teresa Calderón, contaron que la tarea de selección había sido ardua y fascinante, porque debieron sumergirse en más de 400 obras infantiles y juveniles de muy buen nivel literario [...]. Según el registro del jurado, las alumnas y alumnos abordaron el tema que los convocaba desde variados puntos de vista. Algunos lo hicieron desde la ficción, lo ensayístico, poemático, narrativo, desde la oralidad y hasta del concepto lírico de Adán y Eva. Otros tuvieron como soporte la contingencia y sacaron a relucir el femicidio, la realidad familiar, laboral, social y hasta deportiva. ${ }^{13}$

Tomando como base los antecedentes mencionados y la información entregada en el artículo de la Revista de Educación del Ministerio de Educación de Chile, nos proponemos analizar las creaciones infantiles desde el enfoque del análisis de discurso, adhiriéndonos a la idea que el lenguaje escrito refleja cómo es la sociedad que lo utiliza, recogiendo todo lo positivo y negativo de la misma. Así también, puede ser una herramienta que trasmite y ayuda a construir una nueva visión del mundo que nos rodea, es decir, libre de estereotipos y discriminaciones.

Nos proponemos descubrir, a través de los cuatro textos ganadores del concurso, ${ }^{14}$ qué dicen los niños/as y jóvenes chilenos/as en relación a la reciprocidad entre hombres y mujeres. Por otra parte, creemos que la elección del tema de estudio, las técnicas de análisis, la interpretación e incluso la forma de escribir y presentar los resultados reflejan relaciones de poder; situación que nos ha tenido en constante tensión, especialmente al tratarse como material de análisis textos creados por niños y niñas para un concurso de creación literaria. Por esta razón es que se considera de suma importancia llevar a cabo una investigación empática, respetuosa y no autoritaria, por lo que los textos solo actuarán como referentes para inferir las representaciones y conceptualizaciones de hombre y mujer que se pueden interpretar de las creaciones de estos/as niños/as, con el objeto de reflexionar sobre acciones que buscan profundizar en la des-construcción de sistemas inequitativos presentados por los programas de gobierno y en el proceso institucional de generar oportunidades para las mujeres.

Partiendo de la idea de que los seres humanos somos seres culturales, las referencias inmediatas en nuestra socialización son cruciales para construir lo que cada uno/a es y el mundo en que habitamos. Desde esta perspectiva creemos que es necesario acercarse a los niños/as desde distintos ángulos y a través de distintas técnicas. En este acercamiento, trataremos de avanzar en develar el solapamiento de sistemas de dominación, progresando en la tarea de romper conceptualizaciones universales que legitiman la subordinación de la mujer. Intentaremos asimismo visualizar que los perfiles que se construyen no sólo sean acomodaciones útiles para un determinado grupo de individuos.

Debemos recordar que los estudios de género implican una reconstrucción de la experiencia de mujeres y hombres para desmontar los roles socialmente asignados. Desde

${ }^{12}$ CHILE, 2009b.

13 CHILE, 2009c.

${ }^{14}$ Los textos ganadores se encuentran publicados en la Revista de Educación del Ministerio de Educación de Chile (CHILE, 2009c). 
aquí, los textos analizados nos indican parcialmente cómo se incorpora la perspectiva de género en la educación básica (primaria) y media (secundaria) en Chile, pues ellos presentan personajes, roles, funciones, cualidades, sentimientos, anhelos, representaciones, situaciones y contextos.

En este sentido, nuestra interpretación tendría más bien una función heurística, donde "el análisis de contenido enriquece la vacilación exploratoria, aumenta la propensión al descubrimiento. Es el análisis de contenido 'para ver'". ${ }^{15}$ En este trabajo la unidad de registro, "la unidad de significación que se ha de decodificar", ${ }^{16}$ es el tema, definido por Berelson, como "una afirmación sobre un sujeto. Es decir, una frase, o una frase compuesta, habitualmente un resumen o una frase condensada, tras la que puede resultar afectado un vasto conjunto de formulaciones singulares". ${ }^{17}$ Para efectos de este trabajo hemos privilegiado la presencia y no la frecuencia del tema.

\section{Género, socialización y educación}

Respondiendo a una perspectiva foucaultiana, el discurso no es más que la presencia represiva de lo que no se dice, y ese no dicho sería un vaciado que mina desde el interior todo lo que se dice..$^{18}$ Por esto, Foucault nos insta a

estar dispuestos a coger cada momento del discurso en su irrupción de acontecimientos; en esa coyuntura en la que aparece y en esa descripción temporal que le permita ser repetido, sabido, olvidado, transformado, borrado hasta en su menor rastro, sepultado muy lejos de toda mirada, en el polvo de los libros. No hay que devolver el discurso a la lejana presencia del origen; hay que tratarlo en el juego de su instancia.

En este contexto, en la construcción de la vida social se hace uso de argumentos legitimadores que otorgan sustento a dichas construcciones; estos legitimadores surgen muchas veces de las creencias religiosas, la filosofía, la política o la historia. Al estar legitimados, los seres humanos los conciben como inevitables en el desarrollo de la vida personal y social. Berger ${ }^{20}$ puntualiza que las construcciones ocurren porque está en "la naturaleza de las cosas" dotarlas de status ontológico, por cuanto son difíciles de reconvertir o de explicitar, ya que son parte de lo que "es", es decir, estables e inmutables, situándose más allá del esfuerzo individual o social en un determinado espacio histórico. Es así como podemos entender la mantención durante tanto tiempo de una estructura que ha dejado fuera a la mitad de la humanidad.

Según indica Rosa Cobo, las teorías del consenso sostienen que el hecho que las mujeres deseen aquello que exige de ellas el patriarcado se inicia en las experiencias más tempranas, aquellas que se derivan del apego a los referentes inmediatos: padres/madres, educadores/as. Es en esta socialización donde los/as niños/as adoptarían las normas socialmente definidas para su sexo, en este sentido los procesos de sexualización serían primordiales en la reproducción del sistema patriarcal. ${ }^{21}$

No podemos olvidar que la actual tradición educativa proviene de un pensamiento disociado y positivista, que se ha limitado a la entrega de información. Una educación escolarizada ${ }^{22}$ que se arroja para sí misma la responsabilidad de formar a las nuevas

${ }^{15}$ Laurence BARDIN, 1987, p. 22

${ }^{16}$ BARDIN, 1987, p. 79.

17 BERELSON citado por BARDIN, 1987, p. 79

${ }^{18}$ Michel FOUCAULT, 1979

19 FOUCAULT, 1979, p. 41.

20 Peter BERGER y Thomas LUCKMANN, 1993.

${ }^{21}$ Rosa COBO, 1998.

${ }^{22}$ Iván ILLICH, 1974. 
generaciones, además de constituirse como la solución y la vía para satisfacer el afán de dominar el mundo, ${ }^{23}$ siendo las ideologías sexuales útiles para legitimar las diferencias entre varón y mujer que la sociedad asigna. En este marco, Dewey ${ }^{24}$ insiste en que la educación es más que un medio, pues en ella la comunidad y las sociedades son. De ahí que cobran sentido las acciones de equidad de género que exigen de ella una deconstrucción de su propio patrimonio acumulado. ${ }^{25}$ Chomsky, por su parte, agrega que "Ias escuelas son las instituciones responsables del adoctrinamiento de los jóvenes. Los miembros del rebaño tienen que ser rigurosamente adoctrinados en los valores e intereses de tipo privado y estatal-corporativo". ${ }^{26}$

Para que la tarea educativa rearme moral y éticamente al ser humano y a las sociedades, es preciso que sea un espacio de aparición a y con los/as otros/as, ${ }^{27}$ y por tanto un espacio de acción de las tramas de los asuntos humanos y de sus relaciones, es decir, una práctica de la buena vida. En esta perspectiva, el aprendizaje debería ser circunstancial y ajustarse a las demandas del contexto; por lo cual se requeriría que el aprender, conceptualizado como aprehender, sintetizar, dominar, fuera modificado, pues no ayuda al bienestar de las colectividades y menos aún a una buena relación entre hombres y mujeres. ${ }^{28}$ Desde aquí surge la necesidad de un fuerte despliegue en todos los frentes, capaz de constituir una importante palanca en la disminución de la estratificación de los sexos. ${ }^{29}$ En este sentido, consideramos que deberíamos desarrollar "nuevos modos de relacionarnos entre nosotros y con la naturaleza en el futuro"..$^{30}$

En relación a la descolonización de la educación y al avance en el saber como vida, Amorós agrega que

El sistema de género-sexo como matriz que configura la identidad, así como la inserción en lo real de hombres y mujeres, es inseparable de su puesta en cuestión como sistema normativo: sus mecanismos, como los de todo sistema de dominación, solamente se hacen visibles a la mirada crítica extrañada; la mirada conforme y no distanciada los percibe como lo obvio [...], es decir, ni siquiera los percibe.

Para ser fieles a este proyecto, concordamos en que no se debe desvincular el concepto de género y el contexto o intención de su primera formulación, debemos por tanto ligar este concepto al feminismo, para no ser cómplices en este trabajo, de la despolitización de una categoría cuyo objeto era explicitar una normativa de desigualdad entre hombres y mujeres. Desde esta perspectiva, la lectura de obras literarias y de cualquier otro discurso adquiere una interpretación diferente a la lectura que se podría hacer desde la perspectiva despolitizada. Esta actitud de permanente crítica y análisis responde a una necesidad, por cuanto

la ideología patriarcal está tan firmemente interiorizada, sus modos de socialización son tan perfectos, que la fuerte coacción estructural en que se desarrolla la vida de las mujeres presenta para buena parte de ellas la imagen misma del comportamiento libremente deseado y elegido.

${ }^{23}$ Grimaldo RENGIFO, 2003

${ }^{24}$ John DEWEY, 1995.

${ }^{25}$ Martín HOPENHAYN, 2009.

${ }^{26}$ Noam CHOMSKY, 2001, p. 31

${ }^{27}$ Hannah ARENDT, 1993.

${ }^{28}$ RENGIFO, 2003

${ }^{29}$ COBO, 1998

${ }^{30}$ BENHABIB citada por Celia AMORÓs, 2007, p. 16.

${ }^{31}$ AMORÓS, 2007, p. 16

${ }^{32}$ AMORÓS, 2007, p. 61 
Queda clara la dificultad de tal tarea, sin embargo el no hacerlo significaría imitar este modelo, situación que es confirmada por Blanco, indicando que "no hacer nada significa, en la práctica, reproducir lo ya existente, y educar a las alumnas para reproducir modelos que son limitados, que con frecuencia son discriminatorios pero que, por encima de todo, no son suyos". ${ }^{33}$

En la posibilidad de ir más allá, la coeducación hace referencia al hecho de que a niños y niñas se les impartan idénticos contenidos y se eduquen en las mismas actitudes y destrezas a unas y otros. Sin embargo, Vega sostiene que, "En nombre de la supuesta coeducación, en muchas ocasiones lo que se está promoviendo y ejecutando es la normalización e institucionalización del modelo masculino". ${ }^{34}$ Se postula por tanto que la educación, específicamente en la cultura escolar, perpetúa formas de comportamiento tradicional.

Al respecto, Rodríguez enfatiza que

si bien los niños y niñas pueden traspasar las fronteras de género pues son constructores/ as activos/as de su propia identidad, también necesitan mantener una seguridad en su identidad de género, por lo que unos y otras refuerzan los patrones de género establecidos por el orden social. ${ }^{35}$

Así niñas y niños construyen y reconstruyen el mundo social donde están insertos, a través de una continua e inconclusa comprensión de él. En este contexto, la aparición de femineidades más autónomas será vista como desviada y objeto de exclusión, así también las masculinidades más colaborativas. No cabe duda que todo esto conlleva profundos efectos.

Podemos entender que para llegar a ser hombres y mujeres, y en un mundo ideal, cada persona debería tener acceso a esos disímiles caminos de ser. No obstante, en el mundo real esto no es así. "La oposición hombre/mujer ejerce su influencia en el proceso de configuración de la identidad [...] la sociedad ha elaborado un discurso de género que divide a hombres y mujeres en dos categorías opuestas". ${ }^{36}$ Este es un pensamiento que se desprendería de la lógica cartesiana de la separación y jerarquización.

\section{El discurso de los textos}

Desde la perspectiva de Foucault, los textos ganadores del primer concurso de género definen, en sus reglas de formación y en sus condiciones de existencia, los elementos de significación de que disponen los/as niños/as y jóvenes en una época dada o en los discursos disponibles y pronunciados. A través de su práctica discursiva no sólo forman los objetos y relaciones, sino que van más allá, haciendo que funcionen como reglas, prescribiendo lo que debe ponerse en relación y a que objeto referirse, de modo de poner en juego un determinado enunciado. ${ }^{37}$ En ese ir más allá, los textos revelan la existencia de una normatividad construida sobre un sistema social en el que el género es un principio de jerarquización que asigna espacios y distribuye recursos a varones y féminas; los textos ganadores concuerdan en representar en sus personajes y escenarios los estereotipos que participan en la construcción de la identidad del hombre y la mujer. La mayor parte de las categorías, hipótesis, interpretaciones y conocimientos construidos en torno al sexo responden

${ }^{33}$ Nieves BLANCO, 2002, p. 39.

${ }^{34}$ Ana VEGA, 2007 , p. 29.

${ }^{35}$ María del Carmen RODRÍGUEZ y José Vicente PEÑA, 2005, p. 28.

${ }^{36}$ RODRÍGUEZ y PEÑA, 2005, p. 35.

${ }^{37}$ FOUCAULT, 1979. 
a una reproducción del patriarcado (entendido como una organización social o conjunto de prácticas que crean el ámbito material y cultural que favorece la continuidad de la supremacía masculina). ${ }^{38}$ Se observa, además, jerarquización y asignación de atributos históricamente asignados, no visualizándose una generación y un reparto de poderes que se concrete en maneras de un vivir equitativo. Los textos ponen de relieve los prejuicios que inconscientemente se transmiten cuando se asignan determinadas tareas o actividades, o se esperan ciertas actitudes de unos o de otras. Apreciamos que la mayoría de los textos presentó la realidad de la mujer en el mundo privado, no observándose imágenes plurales.

\section{Análisis de los textos}

Al tener claridad hacia donde apuntan los enunciados de los discursos que se revelan en los textos, no podemos quedarnos en sus consistencias, en sus dogmas, pues desde ahí la tarea de des-construirlos se hace imposible, por tanto se requiere amenazar el sistema visibilizando sus códigos, sus olvidos, sus inercias, descubriendo su enigmático tesoro. Debemos definir cada objeto y relación, haciendo referencia a las reglas que permiten su formación y su permanencia en la historia que posibilita su propagación. ${ }^{39}$

Las interpretaciones aquí realizadas serán parciales y situadas, construidas y específicas. Reconocemos que nuestra posición influye inevitablemente sobre los resultados de la investigación y que, por tanto, ésta no es neutral. Coincidimos con la idea que el saber se construye socialmente y por tanto rechazamos la imagen de un/a investigador/a como experto/a omnipotente y poseedor de la verdad.

Los textos ganadores corresponden a la modalidad de poesía y cuento; así como a las categorías infantil y juvenil.

\section{Texto 1}

El cuento ganador en categoría juvenil, Mi madre, narra, desde la perspectiva de uno de los hijos, la historia de una familia en que el padre muere, desde entonces la madre se hace cargo de sus tres hijos y en base a mucho esfuerzo, buenos ejemplos y consejos logra sacar adelante a su familia. Este relato es presentado en primera persona, siendo los protagonistas la madre y su hijo. Se aprecia un texto más bien lineal, sin elementos que sorprendan al lector/a. Su autor, José Pablo, estudia en el Instituto Inmaculada Concepción de la ciudad de Valdivia.

\section{La idea de mujer asociada a madre}

“En ese momento nos tomó a los tres y nos dijo: 'Todo estará bien'. No entendí el significado de esas palabras, no entendía nada, pero luego de un tiempo, logré entender lo que significaban aquellas palabras que me había dicho mamá". El personaje de la mujer como madre es una persona que entrega certezas, otorga seguridad y amparo. Su construcción de identidad se hace desde su rol de madre, una madre que se ajusta a las necesidades de los hijos, es decir, el estereotipo de madres que son los puntales y que buscan las estrategias para que todo marche bien. La construcción de lo femenino se hace desde el modelo del rol "reproductor" y "protector", roles establecidos de acuerdo a los mandatos sociales y culturales.

El personaje de la mujer construida por el joven escritor posee todas las cualidades históricamente otorgadas a una mujer, entre ellas la abnegación, la persistencia y el sacrificio. Una mujer que se presenta definida por su capacidad de dar todo sin esperar nada,

${ }^{38}$ Alicia PULEO, 1998.

${ }^{39}$ FOUCAULT, 1979. 
"Aunque mis hermanos no le devolvieran la mano, nunca nos iba a abandonar". El joven manifiesta en su relato que las mujeres-madres siempre estarán ahí, a pesar de establecer relaciones desiguales, en el sentido de que ellas dan, aunque no se les dé nada a ellas. Esta característica estaría en su naturaleza.

El estereotipo reproducido por el joven va más allá aún: la mujer debe ser fiel a los hijos, pero también a la persona a la que se unió, aunque el otro ya no esté presente. "Ella salió adelante, por eso es que yo la admiro, nunca tuvo otra pareja aparte de papá, porque piensa que puede hacerle daño a Camila o a Max o incluso a mí". Queda claramente definido el carácter coactivo de estas construcciones de la identidad femenina. "Mi madre nunca olvidó a papá, e incluso, lo visitamos todos los meses para que nunca le falte una flor y mi madre le da gracias todos los días a Dios porque tiene hijos como nosotros".

La mujer queda limitada al espacio privado en su identidad como madre-esposa. Ella es en este relato la "súper mamá", su personaje está suscrito al rol materno, de cuidadora a lo largo de toda su vida y parece haber nacido para esto, "en cuanto a mi madre, abrió un hogar para niños huérfanos que buscan una salida a sus vidas". La maternidad es la base fundamental para establecer la identidad femenina en esta narración.

\section{La súper mujer desgarrada}

"Mamá es de esas personas que no defrauda, a pesar de su apariencia desgastada que siempre aparentaba estar muy cansada o estresada". En el relato elaborado por este joven, aparece explícita la existencia de una "súper mujer", en términos de Castell. ${ }^{40}$ Una mujer cansada, estresada, agotada, que debe realizar múltiples tareas las 24 horas del día. Una mujer que se desagarra para cumplir su rol de madre, trabajadora remunerada, dueña de casa. Llama la atención esta opción narrativa que encierra una serie de atributos encaminados a constituir una definición de mujer que todo lo hace, similar a la feminidad hegemónica definida en nuestra sociedad.

El ambiente creado y las relaciones que en él confluyen son muy semejantes a la realidad que viven muchas mujeres en la actualidad. Esta recreación posiblemente muestre el precio que deben pagar las mujeres por el funcionamiento del actual sistema económico:

el sustento de la casa se fue haciendo cada vez más difícil, ya que con el sueldo de mamá no alcanzaba para ella ni para nosotros tres. Tuvo que buscar un segundo trabajo, el cual se le hizo muy difícil, ya que no tenía que coincidir con su actual empleo, ni tampoco tocara con las horas que ella compartía con nosotros.

El personaje debe compatibilizar sus múltiples labores, es decir, ser flexible. Entendemos que esta construcción de flexibilidad responde a un modelo que mantiene las estructuras de poder. El escritor, en ningún momento de su creación, hace alusión a la negociación o a algún mecanismo que asegurará "el compartir tareas". Todo lo hace la mujer por libre elección. Apreciamos la construcción de un personaje que no renunciará a ninguna de las tareas asignadas o autoasignadas.

Llega a tal punto esta idealización que la madre, a pesar de sus múltiples tareas, cumple sus funciones de madre mucho mejor, es decir, bajo presión las iniciativas son más eficientes "pero no todo salía mal, algunas cosas mejoraron, mi madre estaba más atenta con nosotros y se preocupaba de que no nos faltara nada". Se aprecia la elaboración de un personaje que se ajusta completamente a "la súper mujer" planteada por Castell. Pero ¿estará entre las vindicaciones de la mujer cumplir con este precepto?, si lo que se busca

${ }^{40}$ Manuel CASTELL y Marina SUBIRATS, 2007. 
es universalizar y no atesorar las funciones.

La súper mujer del relato se describe como una excelente proveedora: "la comida era cada vez menos abundante, pero siempre tuvimos qué comer, de eso mi Madre se hacía cargo aunque le fuese difícil", una súper administradora: "El gran día llegó, mi madre, con sus ahorros, comprará una casa más grande que la que nos cobijó en este último periodo de mi vida, con sus dos trabajos", como también una mujer súper fuerte, sustento de la armonía familiar: "Cuando mamá oyó esas palabras se puso muy triste y comenzó a llorar. Recuerdo que se encerró en su pieza y yo me quedé varias horas ahí, esperando que saliera para poder estar con ella, como ella estuvo conmigo, pero mamá estuvo cinco horas sin salir y cuando nos fuimos a acostar, ella salió", súper estable emocionalmente, súper amiga y súper confidente: "Yo adoro a mamá, no quiero que sufra ni que le pase nada, yo en ella veo la esperanza de esta familia, una amiga, una confidente".

Finalmente, en los personajes secundarios y su guión de futuro se evidencia una separación tradicional de las actividades, es decir, las que están asociadas a lo masculino y con mayor prestigio social, y las actividades asociadas a lo femenino como una extensión de las tareas del hogar: "yo me gradué como un famoso doctor, Max es abogado y Camila es una diseñadora de moda".

\section{Texto 2}

La poesía ganadora en categoría juvenil, Pensamiento, hace referencia a conceptos como igualdad, fraternidad y dignidad. La autora plantea una revolución que nace desde si misma, ejemplificándola con la historia de dos jóvenes. Su autora, de nombre Paola, pertenece al Liceo de Cultura y difusión artística de la ciudad de Talca. Ella presenta un texto en primera persona, haciendo uso extensivo de su imaginación.

\section{El amor romántico}

"A la tibieza de la desilusión/ cuando no he recorrido nada,/ y tengo demasiados sueños pendientes". La experiencia subjetiva de la emoción y del afecto son los elementos que marcan la producción de esta joven. El amor es la ilusión que mueve las representaciones y cogniciones. La esperanza del amor impulsa a buscar explicaciones que puedan confirmar la premisa de ser amada. "¿Se supone que allí debe haber alguien a mi lado?/ ¿Y si está sólo la mitad escrita en una hoja manchada, /doblada y pisada, escondida en cajas vacías/ y usadas para llorar?/ Debo tener mi complemento". Se visualiza la imperiosa necesidad de estar con otro, pues de lo contrario no existe sentido para estar. La construcción del sujeto femenino se hace en el amor y desde el co-habitar con el otro.

"Un día cuando andábamos volando/ de pronto mi alma apareció/ yo comencé a gritar,/ creía que ella no volvería nunca más/ había quedado complicada". La autora recalca que el amor es el motor, la posibilidad de vivenciar la existencia. El texto poético asocia a la mujer como tradicionalmente se hace al amor, el cual representa la piedra angular de la construcción social de la felicidad. En esto, el texto no escapa como lo señala Neves ${ }^{41}$ de la idea de señalar el amor como la suprema vocación de la mujer, que puede ser comprendido como un ideal que en ocasiones castra su autonomía.

"Yo le quité sus girasoles./ y él tomó mis hojas y escribió con su lápiz todos sus/ bemoles./ Yo me quedé con sus girasoles/ y él arrancó de mi las hojas./ Ahora cada cual tiene lo suyo,/ ahora cada cual tiene lo nuestro". Podemos interpretar que el ideal romántico

${ }^{41}$ Ana Sofia Antunes das NEVES, 2007 
del amor afecta mucho más a las aspiraciones de la mujer, ella entrega más, entrega "sus hojas" donde él escribe. Ella sólo se queda con los girasoles (flores que se marchitan con el tiempo). Podríamos pensar que este amor descrito en el poema de la joven engendra una idea de conspiración, pues el varón la cubre de sueños e ilusiones, arrebatándole la autoría de su propia vida. "Y él tomó mis hojas y escribió". Se advierte, sin embargo, el ejercicio de otorgar mayor paridad al acto del amor, hasta una casi simetría.

"El joven del lápiz al hombro/ y de los girasoles en las manos/ había murmurado en un reducido espacio que como/ joven revolucionario no esperaba a que todo esto siguiera". Los versos parecieran indicar, desde nuestro punto de vista, que es "él" quién define o legitima un cambio en sus relaciones, como si fuera un designio suyo.

\section{La despolitización del feminismo}

"Al final de cuentas iqué significa/ que cada hombre sea igual?/ A lo mejor una mujer/ es igual también./ Aún no resuelvo esta diferencia de géneros". La autora desea dejar claro sus incomprensiones frente a la categoría de género. Extrapolando, esta problemática puede surgir por la pérdida de la memoria histórica de los grupos oprimidos y por los malentendidos de una supuesta igualdad alcanzada. Los versos representan un discurso algo abstracto sobre su propia situación de subordinación y constituyen un claro ejemplo de las consecuencias de la despolitización del concepto de género, por cuanto este termina convirtiéndose en un eufemismo que invisibiliza las estructuras de dominación, situación a la que Rosa Cobo denomina sustitución de feminismo por género. ${ }^{42}$

"Quiero que este género se pueda/ moldear y traspasar a muchas hojas/ llenas de pensamientos y hechas de a cuatro o mil/ personas más". Sin embargo, ella manifiesta cierta claridad que el género-sexo es una construcción y no una situación dada y natural, y nos habla de un movimiento, no de un proceso en solitario o privado, sino más bien público.

\section{Texto 3}

El cuento ganador en categoría infantil, El nuevo colegio, narra la historia de un niño campesino muy pobre que no asiste a la escuela y cuyo mayor deseo es aprender a leer. Este niño cuida de su hermanita realizando las labores de la casa que su madre le ha enseñado. Finalmente el protagonista cumple su sueño de poder estudiar gracias al anciano director de la escuela. Francisca, su autora, pertenece a la Academia lquique, de la localidad de Alto Hospicio; ella nos presenta su cuento desde un narrador omnisciente, con personajes simples, pero logrando por momentos sorprender las expectativas del lector.

\section{Roles atribuidos}

"En sus 10 cortos años ya había pasado por muchas experiencias que sus papás decían que le servirían de mucho en la vida, como por ejemplo: él ya sabía cómo preparar el desayuno a su hermanita pequeña y lo hacía levantándose muy temprano en las mañanas". La autora crea un personaje al cual le atribuye algunas características y actividades que están más asociadas a lo femenino. Ella logra hacer esta transposición, evidenciándose tal vez una construcción de igualdad en las tareas domésticas. En esta equidad, la mujer-madre en el cuento es la encargada de construir estas nuevas relaciones. "También sabía lavar, planchar y coser su ropa y podía realizar cualquier tarea del hogar, porque su mamá desde pequeñito le había enseñado que los quehaceres domésticos era un trabajo igual para hombres como para las mujeres". El hombre adulto no aparece en la

${ }^{42}$ COBO, 2005.

584 Estudos Feministas, Florianópolis, 19(2): 573-590, maio-agosto/201 1 
redefinición de las relaciones. Es la mujer quién debe asumir esta responsabilidad social. Esto nos permitiría inferir entonces que la construcción de nuevas y distintas relaciones en el mundo privado sería más bien una obligación de ella y no de él y tampoco pública.

La idea anterior se ve reforzada con la descripción de las actividades que se asignan al personaje de la madre en el relato: "lo había hecho ella misma con unas viejas cortinas de la casa que ya no servían". El personaje no escapa de los estereotipos creados por la cultura dominante. Ella es la encargada de enseñar, de educar a los hijos, de administrar, de realizar las labores de la casa, además de ayudar en la dimensión económica de la supervivencia de la familia. Así lo manifiesta la autora, reafirmándolo con la cita "mientras sus papás ya cosechaban la tierra en medio de los campos de trigo del patrón del lugar". Este personaje caracteriza a una mujer multidimensional, que asume más deberes y responsabilidades que el hombre.

Destaca en el relato que el personaje que detenta un mayor status social, cultural y económico es un hombre: "Don René, el Director del colegio, daba su respectivo paseo por el patio cuando entre medio de unos arbustos vio un niño en una bicicleta". En el guión, los roles son muy similares a la realidad que viven niños y niñas. La autora del cuento no sobrepasa lo que la realidad le muestra persistentemente, por cuanto los cargos directivos son ocupados mayoritariamente por hombres, por lo que tal vez la niña no pueda imaginar otra situación, los hombres en la narración son directores o dueños de los predios agrícolas.

En este relato se puede apreciar que la igualdad, en los sectores vulnerables o rurales, sólo puede ser pensada en el mundo privado, dentro de las cuatro paredes de la casa, donde los niños y niñas tienen como función apoyar en los quehaceres del hogar cuando no asisten a la escuela. Queda la duda sobre cómo continuaría esta historia cuando el personaje - niño - asista a la escuela.

\section{Texto 4}

La poesía ganadora en categoría infantil, El reino del Señor, se remite a hacer una descripción poética de la versión bíblica de la creación del universo. Presentada por un narrador omnisciente, detenta un personaje principal cuya fuerza se mantiene durante todo el relato. Su autora, de nombre Yuyunis, asiste al colegio Particular Santa Marta de la ciudad de Valdivia.

\section{Heterosexualidad}

"En un reino muy cercano/ Un señor muy grande y sabio". La creación poética tiene como eje mostrar la magnificencia de un "Dios", por lo tanto sólo se aprecia la visibilidad de lo masculino. Lo femenino sólo aparece como complemento. Es "él" quién define los tiempos y los procesos. Lo crucial de la creación es su creador "él". Es "él" quién crea, organiza y ordena: "Al hombre y a la mujer creó".

"Sean fecundos y multiplíquense/ El Señor les ordenó/ Ámense como hermanos/ Pues a su imagen Él los creó". La poesía reproduce por completo el mito cristiano de la creación del mundo, explayándose en las tareas que debían cumplir los hombres y mujeres.

Apreciamos que el texto presenta un fundamento ontológico que legitima y explica el patriarcado natural que se sustenta en esencias masculinas y femeninas eternas, basadas en la división sexual o en las conductas que se esperan de ellos y ellas. Refleja un discurso dogmático que impide al lector realizar una lectura activa, reflexiva y crítica, evidenciándose el enunciado del patriarcado como esencia, en un discurso que pone al varón como el "titular nominal o potencial de todo posible poder", ${ }^{43}$ además de prescribir

${ }^{43}$ COBO, 1998 
la heterosexualidad como opción sexual única, negando otras posibilidades; en definitiva, es un discurso que legitima y reproduce que

el proceso de creación de la diferencia sexual es una operación tecnológica de reducción, que consiste en extraer determinadas partes de la totalidad del cuerpo, y aislarlas para hacer de ellas significantes sexuales. Los hombres y las mujeres son construcciones metonímicas del sistema heterosexual de producción y de reproducción que autoriza el sometimiento de las mujeres como fuerza de trabajo sexual y como medio de reproducción.

\section{Conclusiones}

En los apartados anteriores se ha intencionado captar los códigos del patriarcado y del heterocentrismo en los enunciados, así como en el análisis y reflexión de los objetos y relaciones presentes y ausentes; sin embargo también es importante reflexionar en torno a la existencia de reglas explicitas e implícitas en estos discursos, así como su aparición en el contexto público literario. Ellas no han aparecido por mera casualidad, sino que están presentes en la intersección entre literatura y educación, intencionadas por las expectativas que se desprenden de las bases y objetivos del Concurso. Entre ellas, la confianza en visibilizar recursos literarios que desmantelaran prácticas no equitativas. De esta manera, en el análisis individual de los textos (considerando el proceso institucional que se ha llevado a cabo en Chile, así como las acciones previas que sostenían la producción literaria para el concurso) se observa, paradójicamente, una falta de dispersión en las definiciones en torno a la equidad de género. Todo esto, en mayor o menor grado, encaja en el sistema patriarcal.

No obstante, al captar los intersticios que separan un relato del otro, se destaca que el tercer texto permite al lector la posibilidad de reflexionar en torno al tema, además de cruzar dos elementos centrales como son género y clase social. Consideramos que este texto ofrece al menos un intento por desembarazarse de un contexto patriarcal; por otra parte, en el otro extremo de esta degradación, encontramos el dogmático El reino del Señor, texto que anula toda posibilidad de reflexión.

Apreciamos, igualmente, que en todos los escritos se observa la ausencia de una crítica activa y visible de la heterosexualidad, imposibilitándolos como recursos para la coexistencia de enunciados que releven los discursos heteronormativos, no evidenciándose un avance en visualizar el cuerpo fuera de un sistema de representación sexual. ${ }^{45}$

De igual forma, se aprecia una notoria intención moralizante en los textos, lo que podría explicarse por el tipo de lectura que se entrega en las escuelas y que se adscribe a valores socialmente indiscutibles, que no permiten el diálogo genuino con el/a lector/a.

En general, los textos no entregan elementos para la desconstrucción del sistema patriarcal, reduciendo al mínimo los espacios de discusión desde otras prácticas discursivas, situación que preocupa, pues sabemos que en la actualidad contamos con muchos referentes que buscan desalojar modelos no equitativos. No está de más recordar los grandes esfuerzos realizados en Chile y en el resto del mundo, dejando de manifiesto las incongruencias dentro del proceso institucional mismo, que no ha conseguido desmantelar la dicotomía mujer-patriarcado y mucho menos se ha hecho cargo de las problemáticas del saber/poder, limitándose a mantener el status quo, proceso al que Verónica Feliu se refiere como hipocresía capaz de originar una esquizofrenia social. ${ }^{46}$

\footnotetext{
${ }^{44}$ Beatriz PRECIADO, 2002, p. 22.

${ }^{45}$ PRECIADO, 2002

${ }^{46}$ Verónica FELIU, 2009.
}

586 Estudos Feministas, Florianópolis, 19(2): 573-590, maio-agosto/201 1 
Todas estas reflexiones responden a tener en cuenta la secuencialidad ${ }^{47}$ del discurso en sentido lineal, tanto en su producción como en su comprensión. Así los procesos de enunciar e interpretar se hacen acorde a la información precedente. Ello involucra cierta funcionalidad en los procesos últimos (selección de textos ganadores) y su relación con los anteriores (programas de equidad de género y orientaciones para el concurso), desprendiéndose la oportunidad de re-interpretar o corregir información o contenido.

En este marco, el contexto de una obra literaria luce como soporte sobre el cual se construye un entendimiento del texto, involucrando todas las propiedades y atributos de la situación social global y local. Global, por las acciones políticas que buscan la equidad de género en el ámbito público, y local por cuanto se concreta en la interacción con el/la adulto inmediato en el aula y en la escuela. Resulta importante destacar esta situación, pues consideramos que el contexto, además de influir en el discurso, puede modificarlo. En esta lógica destacan los objetivos propuestos para el concurso; sin embargo, creemos que se minimizaron sus influencias, en especial si consideramos la relación docente-estudiante tradicionalmente marcada por la colonización del mundo infantil/juvenil por parte del adulto.

Si bien los textos nos invitan a cuestionar la eficiencia de las acciones emprendidas en el ámbito de la educación institucionalizada, queda de manifiesto en la selección de los relatos ganadores que ellos están confabulados con el sistema patriarcal. No podemos ignorar que estos textos fueron planificados, elaborados, socializados en el aula, actuando el/la docente como filtro. Por tanto, lo importante aquí es poner atención al contexto global, principalmente a las instancias del proceso educativo y de difusión comunicativa, por cuanto los textos deben ser vistos como constituyentes de su situación local, global y sociocultural. En este sentido, ellos expresan claramente la pertenencía contextual explicitada en nuestro análisis de discurso.

Asimismo, resulta interesante reflexionar en torno a cómo un grupo social, el jurado, miembros del mundo literario chileno, interpretan, orientan y categorizan atributos y propiedades del mundo social, en particular los procesos de equidad de género. Aunque queda claro en el análisis, es oportuno mencionar el proceso institucional que privilegia visibilizar los códigos del patriarcado en una actividad que instaba a desmantelarlos. Surgen así múltiples inquietudes, entre ellas: ¿Qué significa que estos textos hayan ganado? ¿Cuál es el sentido, en este contexto? ¿Porqué se dice aquí esto y no aquello? (señalar que la página web del Observatorio de Género y Equidad cuenta como única publicación con el texto ganador El reino del Señor), derivándose implicancias funcionales y explicativas. Entre ellas, la hipótesis que existiría una intencionalidad de parte de algunos/as de consensuar con el sistema patriarcal, pues ellos/as conocen el impacto de estos discursos en sus destinatarios/as (destinatarios/as que se concentran principalmente en los docentes, pues la revista que publicó dichos textos es una revista de educación). En otras palabras, creemos que los textos ganadores constituyeron piezas de ajedrez movidas de una determinada manera con objeto de ganar la partida, dando por resultado el quebrantamiento de procesos institucionales, y haciendo caso omiso a orientaciones y referentes.

Nos atrevemos a concluir que, a pesar del contexto global, aquellos que tenían la responsabilidad de mediar - en términos educativos - en la des-construcción del modelo patriarcal sólo se limitaron a una acción de reproducción meramente informativa, y no ofrecieron experiencias y propuestas educativas orientadas al diseño de acciones concretas en este campo, olvidando el vasto marco teórico, tanto crítico como propositivo, donde se

${ }^{47}$ Teun Adrianus VAN DIJK, 1988. 
destacan los nuevos aspectos de la relación entre los géneros y, por lo tanto, sus nuevos símbolos sociales, situación que desde la literatura ofrece múltiples y valiosas obras que trastocan los modelos tradicionales y confirman la transformación de las representaciones sociales, Rosa caramelo entre ellas.

La reflexión se encamina por tanto a mirar con atención que instituciones como la escuela conducen inevitablemente a la contaminación, hacia el crimen de lo humano y la polarización social, pues su función sólo se limitaría a acelerar procesos donde las necesidades no materiales son transformadas en demandas de bienes y profesionales para satisfacerlas. ${ }^{48}$

Finalmente, consideramos de gran importancia avanzar en la perspectiva de la escritura como práctica pública, asociada a los efectos de lo que se dice por escrito y en la construcción de un interlocutor, y avanzar en la cultura escrita de todos los estamentos, en especial de nuestros/as docentes. En este sentido, al parecer tanto el jurado como los docentes que intervinieron en el proceso del concurso se preocuparon más por las concepciones globales del tema que por la microestructura que lo soportaba. Es decir, se han centrado poco en el tema, y mucho menos en las condiciones de enunciación del texto, preocupándose más del cómo que del qué, y centrándose en una evaluación prescriptiva de los textos de los/as estudiantes.

En este contexto, quisiéramos finalizar con las conclusiones entregadas por un grupo de profesionales colombianos a partir de un estudio cuyo objetivo era apreciar cómo escribían los niños y niñas de su país. Entre ellas se destacan la necesidad de estimular la creación y el mantenimiento de talleres literarios y de escritura creativa; fomentar la reflexión y el debate sobre su teoría y práctica, vinculándolos con las realidades del mundo de hoy, en especial la equidad de género; desarrollar y fortalecer en todo el proceso educativo y de formación literaria el pensamiento crítico e independiente; así como la necesidad de estar bien informado, tanto sobre la compleja marcha del mundo de hoy con sus problemas y desafíos como del entorno nacional y local. ${ }^{49}$

Por último, quisiéramos señalar que quedamos en deuda con un análisis más profundo sobre las masculinidades en las creaciones literarias, temática que debería ser objeto de un nuevo artículo para poder desarrollarlo de la forma que su relevancia demanda.

\section{Referencias bibliográficas}

ABAD, María Luisa. Género y educación: la escuela coeducativa. Barcelona: Editorial Graó, 2002.

AMORÓS, Celia. Teoría feminista de la ilustración a la globalización: de la ilustración al segundo sexo. Madrid: Ediciones Minerva, 2007.

ARENDT, Hannah. La condición humana. 4. ed. España: Editorial Paidos, 1993.

BACHELET, Michelle. Estoy contigo. Programa de Gobierno. Chile, 2006.

BARDIN, Laurence. Análisis de contenido. 2. ed. Madrid: Akal Universitaria, 1987.

BLANCO, Nieves. "Educar mujeres y hombres". Revista Otras Miradas, Mérida, Venezuela: Universidad de los Andes, v. 2, n. 2, p. 80-87, 2002.

BERGER, Peter; LUCKMANN, Thomas. La construcción social de la realidad: la sociedad como realidad objetiva. 11. ed. Buenos Aires: Editorial Amorrortu, 1993.

CASTELL, Manuel; SUBIRATS, Marina. Mujeres y hombres ¿un amor imposible? Madrid: Editorial Alieuka, 2007.

${ }^{48}$ ILLICH, 1974.

${ }^{49}$ COLOMBIA, 2010. 
. Agenda de Gobierno de Chile para avanzar en equidad de género (2006-2010).

Chile, 2006.

Ministerio de Educación. Disponible en: <http://www.mineduc.cl/index.php?id seccion

$=10 \& i d$ portal $=1$ \&id_contenido $=8590>$. Acceso en: 12 mayo 2009a.

Ministerio de Educāción. Disponible en: <http://www.mineduc.cl/index.php?id_seccion

$=2449 \& i d$ pportal $=8 \&$ id_contenido $=8203>$. Acceso en: 20 abr. $2009 \mathrm{~b}$.

Ministerio de Educación. Revista de Educación. Disponible en: <http://www.mineduc.cl/

biblio/documento/200901 121727330.Revista\%20334.pdf>. Acceso en: 17 mayo 2009c. CHOMSKY, Noam. La (des)educación. 10. ed. Barcelona: Editorial Crítica, 2001.

COBO, Rosa. Género: en 10 palabras claves sobre mujer. Pamplona: Editorial Verbo Divino, 1998.

. "El género en las Ciencias Sociales". Cuadernos de Trabajo Social, Madrid: Ediciones

Universidad Complutense de Madrid, v. 18, n. 249, p. 249-258, 2005.

COLOMBIA. Ministerio de Educación. Concurso Nacional de Cuento. Disponible en: <http:/ /www.colombiaaprende.edu.co/html/home/1592/articles-184955_recurso_2.pdf > . Acceso en: 15 mayo 2010.

DEWEY, John. Democracia y educación. 14. ed. Madrid: Ediciones Morata, 1995.

EL MERCURIO. 30 marzo 2009. Disponible en: <http://w3app.mineduc.cl/mineduc/genero/ documentos/Ine\%20escasa\%20ayuda\%20de\%20varones.pdf $>$. Acceso en: 18 mayo 2010.

FELIU, Verónica. “¿Es el Chile de la post-dictadura feminista?”. Revista Estudos Feministas, Florianópolis, v. 17, n. 3, 2009. Disponible en: <http://www.scielo.br/scielo.php?script= sci_arttext\&pid=S0104-026X2009000300004\&Ing =es\&nrm =iso > . Acceso en: 18 mayo $20 \overline{10}$.

FOUCAULT, Michel. La arqueología del saber. 6. ed. España: Editorial Siglo XXI, 1979.

HOPENHAYN, Martín. "La educación intercultural: entre la igualdad y la diferencia. En poder de la diversidad cultural". Pensamiento Iberoamericano, España: Ediciones AECI y Fundación Carolina, n. 4, p. 49-72, 2009.

ILLICH, Iván. La sociedad desescolarizada. 2. ed. Madrid: Editorial Barral, 1974.

KRIPPENDORFF, Klaus. Metodología de análisis de contenido: teoría y práctica. Buenos Aires: Editorial Paidos Comunicación, 1997.

NEVES, Ana Sofia Antunes das. "As mulheres e os discursos genderizados sobre o amor: a caminho do 'amor confluente' ou o retorno ao mito do 'amor romântico'?". Revista Estudos Feministas, Florianópolis, v. 15, n. 3, 2007. Disponible en: <http://www.scielo.br/ scielo.php?script $=$ sci_arttext\&pid $=$ S0104-026X2007000300006\&lng $=$ es\&nrm $=i s o>$. Acceso en: 24 mayo 2009.

OBSERVATORIO DE GÉNERO Y EQUIDAD. Disponible en: < http://www.observatoriogeneroylide razgo.cl/index.php?option $=$ com_content\&task $=$ view\&id $=134 \& l t e m i d=2>$. Acceso en: 19 mayo 2010.

ONU. Objetivos de Desarrollo del Milenio. Disponible en: <http://www.un.org/spanish/ millenniumgoals/gender.shtml>. Acceso en: 1 abr. 2009.

PRECIADO, Beatriz. Manifiesto contra-sexual: practicas subversivas de identidad sexual. Madrid: Editorial Pensamiento Opera Prima, 2002.

PULEO, Alicia. Patriarcado: en 10 palabras claves sobre mujer. Pamplona: Editorial Verbo Divino, 1998.

RENGIFO, Grimaldo. La enseñanza de estar contento: educación y afirmación cultural andina. Lima: Pratec, 2003. 
RODRÍGUEZ, María del Carmen; PEÑA, José Vicente. "La investigación sobre el género en la escuela: nuevas perspectivas teóricas". Teoría de la Educación-Revista Interuniversitaria, España: Ediciones Universidad de Salamanca, n. 17, p. 25-48, 2005.

SERNAM. Plan de Igualdad de Oportunidades para Mujeres y Hombres: Lineamientos Generales 2000-2010. Santiago de Chile: Gobierno de Chile, 2000.

. SERNAM. Evaluación Primera Fase 2000-2005 del Plan de lgualdad de Oportunidades entre hombres y mujeres 2000-2010. Santiago de Chile: Gobierno de Chile, 2005.

VAN DIJK, Teun Adrianus. Texto y contexto. Madrid: Editorial Cátedra, 1988.

VEGA, Ana (Coord.). Mujer y educación: una perspectiva de género. Málaga: Ediciones Aljibe, 2007.

[Recebido em 21 de julho de 2009 e aceito para publicação em 3 de setembro de 2010]

\begin{abstract}
Analysis of Young Writers' Literary Texts: Towards the De-Construction of Patriarchal Codes in Chile

Abstract: This article presents a reflection from the perspective of feminism as a critical theory, attempting to make visible distortions in the perspective of gender. The analysis is based on the winning texts of the first contest of children's literature from a gender perspective, implemented and coordinated by the Ministry of Education of Chile in 2008. The questions which guided this study were: What do girls and boys say about gender relations in their literary creations? Why were the 4 texts selected as winners? Among the most significant findings is the fact that, despite considerable changes in the global context, the winning texts reassert the patriarchal system, not incorporating other discursive practices which are present in the national and international contexts.

Key Words: Gender; Equity Policies; Children's Literary Works; Discourse.
\end{abstract}

